\title{
Prescription: A Situation Analysis in Indian Health Care System
}

\author{
Sathish Venkatasamy Dhayalan*, Arulkumaran G, Shalini Sivadasan
}

KMCH College of Pharmacy, Coimbatore, Tamil Nadu, INDIA.

\begin{abstract}
A prescription is the vital written communication from physician to patient, which consist of instruction to pharmacist on dispensing of drug regimen. Prescription writing is a critical task that suggests prescriber's responsibility towards the safe prescribing and monitoring to provide clinical care to the patient thus carries legal implications. Physicians oftentimes scribble down and take shortcuts in writing down drug orders that are not legible. Illegible writing leads to medication errors. Any errors in prescription writing have to be eliminated by addressing properly with regard to its regulations and rationale. Errors due to handwritten prescription can be eliminated by generating prescription using computer or electronic devices. Computerized prescriptions are suggested in many studies which have shown relatively lower rates of error as compared to handwritten prescriptions. It is need of the hour that the proposed changes in the prescription writing regulations should be implemented in a small region as pilot, outcome should be assessed and the final regulation and change to computerization should be implemented throughout the nation.
\end{abstract}

Key words: Prescription writing, Medication errors, Record linkage, Computerised prescription, Personal identification number.

\section{INTRODUCTION}

The prescription is one of the most important communications from physician to patient through pharmacist/dispenser. "Prescription is a written order by the physicians to the pharmacists for the preparation and administration of the drug or medical device to patients". ${ }^{1}$ Prescription should give necessary information to patients and communicate clearly with pharmacist for the preparation of the drugs.

Prescription is dissected into different parts, some of them are mandatory where some of them are important though not mandatory. ${ }^{1}$ The parts prescription include superscription, inscription, subscription and signature. The superscription or heading has the symbol " $\mathrm{R}$ " or " $\mathrm{Rx}$ " which means to recipe (in Latin, to take). ${ }^{2}$ Followed by inscription, which contains the names and quantities of the ingredients. ${ }^{2}$ Followed by subscription gives the directions to the pharmacist for compounding the drug. ${ }^{2}$ Followed by the signature, which is preceded by the sign "s" standing for signa, which gives the directions for use of drugs to patients. ${ }^{2}$ Finally, the handwritten signature of the prescriber to make the prescription valid. ${ }^{2}$

Prescription writing is a critical task that suggests prescriber's responsibility towards safe prescribing and monitoring to provide clinical care to the patient thus also carries legal implications. ${ }^{3,4}$ The several notifications from the government and the medical council leave many of the medical practitioners confused on how to write the prescriptions. There are many essential and legal requirements that need to be followed by the practitioners while writing a prescription. ${ }^{1}$ Every state has their own requirements for prescriptions but most follow a similar format.
Submission Date: 14-08-2020; Revision Date: 02-02-2021; Accepted Date: 12-04-2021

DOI: 10.5530/ijper.55.2s.104 Correspondence: Dr. Sathish Venkatasamy Dhayalan Lecturer, KMCH College of Pharmacy, Kalapatti Road, Coimbatore-641048, Tamil Nadu, INDIA. Phone no: *91-2369302 Email id: sathish190795@ gmail.com

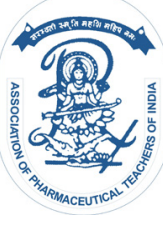

www.ijper.org 


\section{Prescription regulations}

Medical Council of India was established in 1934 under the Indian Medical Council Act, 1933. The council's Professional Conduct, Etiquette and Ethics Regulations 2002 (clause 1.3, 1.4 and 1.5) briefs about maintenance of medical records, display of registration numbers and use of generic names of drug., ${ }^{5,6}$ Clause 1.3.4 states that "Efforts shall be made to computerize medical records for quick retrieval". As per the clause 1.5 of the regulations, 2002 , every physician should use generic names as far as possible and he/she should ensure that the use of drugs is rational. ${ }^{6}$ Clause 1.5 was modified and notified in the Gazette of India on 08.10.2016 and stated that "Every physician should prescribe drugs with generic names legibly and preferably in capital letters and he/she shall ensure that there is a rational prescription and use of drugs" 7,8

The Indian Medical council circular India No. "MCI211(2)(Gen.)/2017-Ethics/104728" dated April 21, 2017 cautioned "any doctor found violating Clause 1.5 of the ethics regulations with suitable disciplinary action by the concerned state medical council or by the Indian Medical Council" and also requested all registered Medical Practitioners under the Indian Medical Council Act to give wide spread publicity of the above regulation to ensure that all the doctors practicing medicine under their jurisdiction comply with the regulation. ${ }^{9}$ These regulations and circulars are obscure and dissuade from the purpose, as it nowhere defines the term "generic drug" and when the authors asked for further clarification on the term generic drug through RTI, the MCI vaguely provides a web reference for the term by WHO which is not available now. ${ }^{8}$ And also, these circulars do not provide clear explanation about prohibiting the use of trade names and generics with brand names in a prescription. ${ }^{8}$

\section{Partial Prescribing}

The Union health ministry of India in 2016 allowed pharmacists to prescribe medicines in primary healthcare centres (PHCs) for treating minor ailments in the rural areas. Indian Pharmacists Association (IPA) has been suggesting to the ministry to bring this reform in the health care sector for the welfare of the patient community for some time now. In states like Punjab, Uttarakhand and Himachal Pradesh the local governments have already allowed pharmacists to prescribe medicines for minor ailments. ${ }^{10,11}$

In 2018, various amendments to the National Medical Commission Bill have been approved by the Union cabinet. The NMC Bill is a wide-ranging legislation for reform in medicine. According to the bill, "The mid-level medical practitioners will get a limited license to practice specified medicines in primary and preventive healthcare settings and in other settings under the supervision of a medical doctor". These mid-level medical practitioners include nurses with specific training, pharmacists, physician assistants and optometrists. ${ }^{12}$

\section{Prescription writing - current scenario}

Countries that top the ranking in human development index by United Nations abide stern regulations in health sector, like computerised prescription orders and e-prescriptions, which primarily circumvents from dispensing error due to illegible handwriting. This practice of maintaining prescriptions and other medical histories in a centralised database greatly helps in continuous recording of drug use thereby analysing the pattern of drug use year to year and also between countries. ${ }^{13}$ As per the reports from Medication Errors released in StatPearls in the year 2003, "illegible or unclear prescriptions result in more than 150 million calls from pharmacists to physicians, asking for clarification, Which is a timeconsuming process that could cost the healthcare system billions of dollars a year in wasted time in the United States". ${ }^{14}$ And also states that the error occurring due to poor handwriting has been resolved with the help of computers and devices to print the prescription. ${ }^{14}$

The Institute for Safe Medication Practices (ISMP) stated that "electronic prescribing-with proper systems design, implementation and maintenance-can contribute significantly to the prevention of medication errors, Which called for eliminating the handwritten prescription in United States by 2003". ${ }^{5}$

In India illegible writing of prescription has pestering pharmacists, nurses and even physicians for decades. Physicians oftentimes scribble down and take shortcuts in writing down drug orders that are not legible; which paves way for most of the dispensing error and ultimately affects patient health, sporadically results in death. When the prescription is illegible, the pharmacist or other health care worker needs clarification from the prescriber, which is not possible in Indian health care scenario with its patient to doctor ratio, lack of time and lack of system in ensuring the rapport between the physician, nurses, pharmacist and eventually, the pharmacist or health care worker is pushed to best guess the drug orders. It is very crucial to address these gaps to avoid the negative consequences in terms of both health and cost, due to illegible prescription writing.

A cross-sectional study conducted in a tertiary level hospital located at a rural area of Maharashtra state, India from October 2009 to March 2010 reported that $50 \% \quad(n=499)$ of the prescriptions were incomplete and about $17.9 \%$ of the prescriptions were illegible. ${ }^{16}$ 
There are very few studies conducted on prescription errors in the Indian health care system and also lack of nationwide monitoring program on drug use like other developed countries. Another cross-sectional study carried out in Kerala to assess the quality of prescription written by dental and medical students and practitioners covering 345 participants reported that there were no significant differences in quality of prescription writing among medical and dental professionals. ${ }^{17}$

\section{Proposed Strategies to fill the gap}

The current prescription writing practice in Indian health care system evidently shows that laid regulations are not followed. To rationalise the prescription writing, stern regulations should be framed and strict action should be taken if not adhering to these regulations. Regular meeting should be conducted in national, state and hospital level emphasizing the change in regulations and educating the prescribers and pharmacists.

Any errors in prescription writing have to be eliminated by addressing properly with regard to its regulations and rationale. Irrational prescription writing leads to medication errors, resulting in increased morbidity or hospitalization which in turn increases the economic burden. ${ }^{18}$ Computerized physician order entry (CPOE) has been promoted as an important component of patient safety, quality improvement and modernization of medical practice. ${ }^{19}$ This system should be introduced to all the prescribers and made mandate that drugs are dispensed only with the prescription order generated though this platform. ${ }^{20}$ This order entry system should be licensed to the registered prescriber where one can prescribe in generic name or generic name accompanied by brand/ branded generic name, combination drugs with respective dose. ${ }^{21}$

Look Alike and Sound Alike (LASA) drugs can be differentiated by Tall Man Lettering. ${ }^{22}$

Itshouldinclude the diagnosis ormedication'sindication for use, which helps the pharmacist to identify any incorrect dose or irrational use of drugs beforehand. It also should include the validity of the prescription or course of therapy so as to avoid multiple filling with same Prescription.

Individual patient identification number should be followed countrywide. This identification number should be used in medical care database, claims database and other health care databases like (laboratory centres, accident registries, cancer registries, Death registries).$^{13}$ This administrative change will require a huge transformation in the Indian healthcare scenario with its huge implementation cost. But this collective database will be

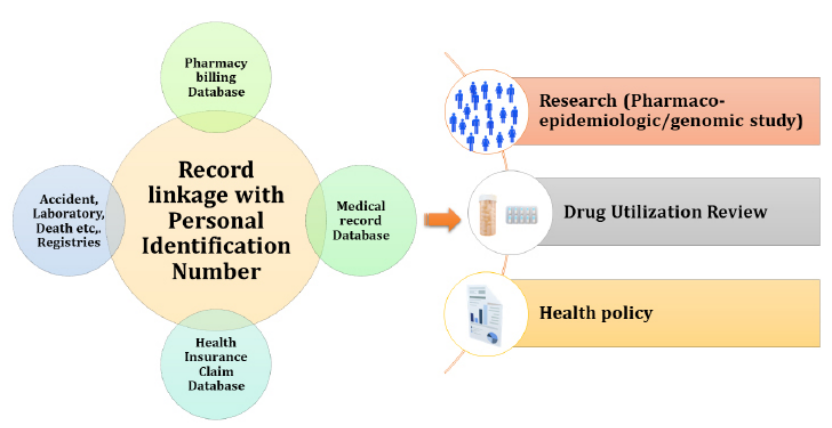

Figure 1: Record linkage with personal identification number (Original).

source for multilevel research, conducting pharmacogenomics study which will help in identifying safe and effective pharmaceuticals and vaccine (Figure 1). And also, to keep track on the nation's health by means of understating the pattern of drug utilization towards the health conditions which in turn helps to create effective drug use policies.

\section{CONCLUSION}

Computerized prescriptions are suggested in many studies which have shown relatively lower rates of error as compared to handwritten prescriptions. ${ }^{23}$ Since prescription errors are abundant and often occur due to illegible writing, prescribers adapting computerized prescription order entry in their daily practice can address the issue. This will greatly help avoiding dispensing error, prescription error and rationalising drug use which improves the patient's health outcome. These changes will be a stepping stone for nation like India to have record on its drug use pattern and keep a track on the people's health. The proposed strategies to fill the gaps and change in prescription writing regulations, can be implemented as a pilot in a region to assess the effectiveness and later this can be implemented with required changes throughout the nation

\section{ACKNOWLEDGEMENT}

The authors thank Dr. A. Rajasekaran, Principal, $\mathrm{KMCH}$ College of Pharmacy for his continuous support and motivation and thank Mr. Easwar Rajah for his assistance.

\section{CONFLICT OF INTEREST}

The authors that there is no conflict interest. 


\section{ABBREVIATIONS}

MCI: Medical Council of India; PHCs: Primary Healthcare Centres; IPA: Indian Pharmacists Association; NMC: National Medical Commission; ISMP: The Institute for Safe Medication Practices; COPE: Computerised Physician Order Entry; LASA: Look Alike and Sound Alike.

\section{REFERENCES}

1. Singhania M. Writing a Prescription: Guidelines. Medicaldialogues.in. 2021. Available from: https://medicaldialogues.in/writing-a-prescription-guidelines? infinitescroll=1

2. Panchbhai A. Rationality of Prescription Writing. Indian Journal of Pharmaceutical Education and Research. 2014;47(4):7-15.

3. Donnelley R. Principles of Prescription Writing and Other Pharmacotherapeutic Considerations. Downloads.Iww.com. 2008. [cited 9 February 2021]. Available from: http://downloads.Iww.com/wolterskluwer_vitalstream_com/sample-content/ 9780781765367_pickett/samples/lwbk088-3870g-03-25-32.pdf

4. Fox A. Prescription writing. 2016. Lecturer Lecturer Uhs.nhs. uk. Available from: https://www.uhs.nhs.uk/media/suhtideal/doctors/ saferprescribingworkbook/section1-prescriptionwriting.pdf

5. Indian Medical Council Act. The Government of India. 1956. Available from: http://legislative.gov.in/sites/default/files/A1956-102_0.pdf

6. The Medical Council of India: Professional Conduct, Etiquette and Ethics, Regulations 2002. The Gazette of India dated 06.4.2002 (Part III, Section 4).Available from: https://www.mciindia.org/documents/rulesAndRegulations/ Ethics\%20Regulations-2002.pdf

7. The Indian Medical council. circular No. MCl-211(2)/2016-Ethics/131118. 2016.

8. Available from: https://www.mca.gov.in/Ministry/pdf/IBBINotification_14062017. pdf

9. Andrade C, Rao T. Prescription writing: Generic or brand?. Indian Journal of Psychiatry. 2017;59(2):133. Available from: http://www.indianjpsychiatry.org/ text.asp?2017/59/2/133/210730
10. The Indian Medical council circular No. MCl-211(2) (Gen.)/2017Ethics/104728. 2017. Available from: https://taxguru.in/wp-content/ uploads/2017/04/MCl-Instruction.pdf

11. Recommendations of the Government-appointed Task Force on Medical Education under the National Rural Health Mission. WP(C) 13208/2009. 2010. Available from: Welcome to High Court of Delhi

12. The Draft Drugs and Cosmetics (Amendment) 2015. Central Drugs Standard Control Organization: Acts and Rules. 2014. [cited 2014 Dec 31] Available from: https://cdsco.gov.in/opencms/opencms/en/Acts-Rules/

13. The National Medical Commission Bill - 2019. Bill No. 185-C of 2019. 2019. [cited 2019 Jul 29]. Available from: https://www.nhp.gov.in/ NHPfiles/185-C_2019_LS_Eng.pdf

14. Ralph E, Sten O, Marie L, Bruce H. Global Drug Surveillance: The WHO Programme for International Drug Monitoring. Text book of Pharmacoepidemiology Part 2, Chapter 8. 2006;118-22. [cited 2006 Dec 05]. Available from: https://doi.org/10.1002/9781118707999.ch8

15. Tariq RA, Vashisht R, Scherbak Y. Medication Errors. In: Stat Pearls. Treasure Island (FL): StatPearls Publishing. 2020. [Updated 2020 Jun 15].

16. Available at: https://www.ncbi.nlm.nih.gov/books/NBK519065/

17. Cohen MR, Smeltzer JL. ISMP Medication Error Report Analysis. Hosp Pharm. 2017;52(6):390-3.

18. Phalke VD, Phalke DB, Syed MMA, Mishra A, Sikch S, Kalakoti P. Prescription writing practices in a rural tertiary care hospital in Western Maharashtra, India. The Australasian Medical Journal. 2011;4(1):4-8. doi: 10.4066/AMJ.2011.515

19. Varghese N, Ramanarayanan V, Janakiram C, Joseph J. Assessment of quality of prescription writing among dental and medical students and practitioners in Kerala. Journal of Natural Science, Biology and Medicine. 2018;9(1):27.

20. Singh B, Batta A. Rational approach to prescription writing: A preview. Neurology India. 2018;66(4):928.

21. Khanna R, Tony Y. Computerized physician order entry: Promise, perils and experience. The Neuro Hospitalist. 2014; 4(1):26-33.

22. College of Dental Surgeons of British Columbia. Prescribing and Dispensing Drugs-Standards and Guidelines. 2017. [Updated 2017 Jan 24]Available from: https://www.cdsbc.org/CDSBCPublicLibrary/Prescribing-and-DispensingDrugs-Standard-and-Guideline.pdf

23. Nuckols T, Smith-Spangler C, Morton S, Asch S, Patel V, Anderson L, et al. The effectiveness of computerized order entry at reducing preventable adverse drug events and medication errors in hospital settings: A systematic review and meta-analysis. Systematic Reviews. 2014;3(1):1-2.

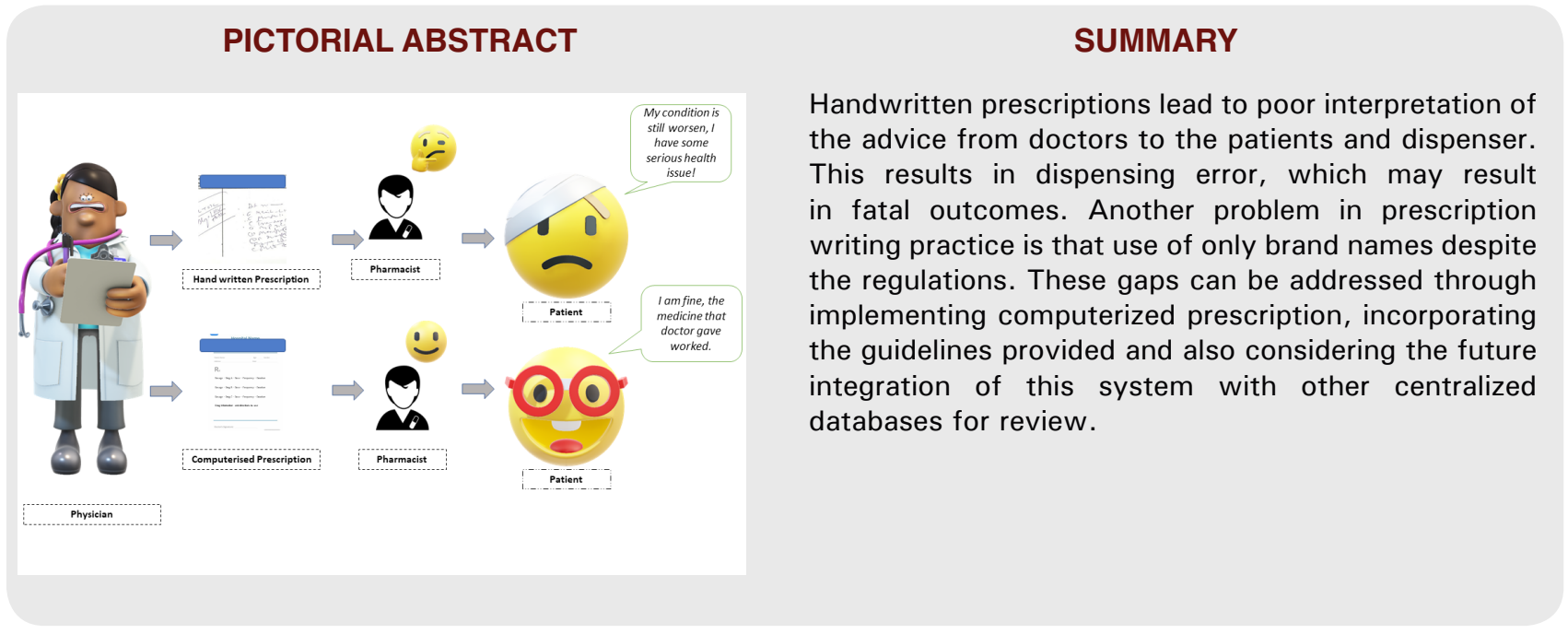




\section{About Authors}

Dr. Sathish Venkatasamy Dhayalan, Currently pursuing Masters of Public Health from James $P$ Grant School of Public Health, BRAC University, Bangladesh. Former Lecturer in Department of Pharmacy Practice, KMCH College of Pharmacy. with keen interest in public health policy making.

Dr. Arulkumaran. G, Currently designated as Principal, K. T. N. College of Pharmacy. Former Vice principal and Head of the Department of Pharmaceutics, $\mathrm{KMCH}$ College of Pharmacy. 25 years of Teaching and Research experience in the field of Pharmacy, with specialty in Pharmaceutics.

Dr. Shalini Sivadasan, Currently designated as Professor and Head, Department of Pharmacy Practice, KMCH College of Pharmacy. 15 years of Teaching and Research experience in the field of Pharmacy, with specialty in Pharmacy Practice.

Cite this article: Sathish VD, Arulkumaran G, Shalini S. Prescription: A Situation Analysis in Indian Health Care System. Indian J of Pharmaceutical Education and Research. 2021;55(2s):s340-s344. 